\title{
"Raton" Edukasi Keragaman Budaya Indonesia Melalui Media Permainan Papan
}

\author{
Bimo Firstiawan Akbar 1, \\ Samuel Gandang Gunanto ${ }^{2}$, Arif Sulistiyono ${ }^{3}$ \\ Program Studi Animasi, ISI Yogyakarta \\ Email: bimo.firstiawan@gmail.com 1, gandang6@gmail.com², arifgokong@gmail.com³
}

\begin{abstract}
Abstrak
Kurangnya arena bermain yang ada di sekitar lingkungan pemukiman serta banyak dari anak-anak maupun remaja yang lebih sering bermain gadget sehingga mengakibatkan kurangnya permainan tradisional yang dimainkan. Boardgame "RATON" merupakan pengembangan dari permainan tradisional bentengan yang telah dimodifikasi.

Terdapat proses-proses yang harus dilewati dalam penciptaan boardgame seperti konsep, pembuatan aturan permainan, prakarya, test play dan packaging. Cara bermainya pun hampir sama dengan permainan tradisional bentengan yaitu untuk merebut benteng musuh dengan cara menempatinya. Terbilang kompleks dalam segi peraturan, namun permainan ini dapat di mainkan oleh banyak orang kraena tidak meninggalkan unsurunsur yang dibuat sebelum permainan ini ada.
\end{abstract}

Kata kunci : boardgame, permainan, raton, tradisional

\begin{abstract}
Lack of playground around the neighborhood and many of the children adolescent who play gadget more than playing an traditional games. "RATON" boardgame is a development of modified traditional games.

There are processes that must be passed in the creation of boardgames such a concept, game rules, crafting, test play and packaging. The way to use it is almost the same as traditional Bentengan game, which is to seize the enemy fort by occupying it. It is complex in terms of regulations, but this games can be played by many people without leaving element made before this game exist.
\end{abstract}

Keywords: boardgame, games, raton, traditional 


\section{PENDAHULUAN}

\section{Latar Belakang}

Permainan tradisional saat ini sudah mulai ditinggalkan karena sudah jarang ditemukan tanah lapang di lingkunagan masyarakat. Permainan tradisional merupakan warisan budaya dari generasi ke generasi. Oleh karena itu kunci keberlangsungan permainan tradisional untuk tetap hidup ditengah masyarakat adalah pewarisan dari generasi tua ke generasi muda. Tapi sebagian besar dari permainan tradisional tidak di kenalkan kepada generasi muda. Karena perilaku masyarakat modern lebih suka pada hal yang praktis.

Era globalisasi ini, memunculkan alternatif permainan berbasis digital. Permainan yang terdapat digital cenderung lebih diterima dan praktis. Permainan atau game dibuat untuk menghilangkan stress, ada juga permainan yang dibuat untuk kegiatan belajar mengajar atau pendidikan, dibuat demikian agar orang yang ingin belajar tidak merasakan bosan. Permainan biasanya melibatkan stimulasi mental atau fisik dan juga bisa keduanya. Banyak permainan yang bisa mengembangkan kreatifitas seseorang.

\section{Rumusan Masalah}

Berdasarkan latar belakang dapat dirumuskan permasalahan sebagai berikut:

- Permainan tradisional Bentengan sudah jarang dimainkan oleh anak - anak karena kurangnya lahan.

- Anak-anak lebih memilih permainan di handphone. Karena lebih menarik dan praktis.

- Kurangnya desain permainan boardgame yang mengambil atau memoidifikasi permainan tradisional dengan unsur yang edukatif, menarik dan praktis.

\section{Tujuan dan Manfaat}

Mengembangkan permainan tradisional Bentengan dengan mengubah skala area Bentengan menjadi ukuran kecil layaknya boardgame dengan memodifikasikan cara bermainnya serta mengenalkan unsur-unsur keberagaman budaya Indonesia sebagai muatan lokal.

\section{Target Audien}

Target audien menurut demografis game ini adalah ;

Usia $\quad: 12$ tahun keatas 
Jenis kelamin : Laki-laki dan perempuan

Pendidikan : Dari latar pendidikan apapun

Status sosial : Semua kalangan

Negara : Indonesia

Bahasa : Indonesia

\section{Indikator Capaian Akhir}

Capaian akhir dari permainan "RATON" yaitu apabila telah melalui tahapan-tahapan produksi, sehingga menjadi satu permainan papan edukasi yang utuh, dengan tahapan sebagai berikut:

- Praproduksi

Praproduksi adalah tahap awal dimulainya pembuatan karya. Mulai dari pengembangan ide hingga pembuatan prakarya.

- Produksi

Produksi adalah proses inti dari pembuatan permainan, proses ini dilakukan setelah tahap praproduksi selesai. Mulai dari pewarnaan asset hingga testing tahap ke-2.

- Pascaproduksi

Pascaproduksi adalah tahapan akhir atau proses penyelesaian, tahap ini berlangsung setelah tahap produksi selesai.

\section{LANDASAN TEORI}

Proses pengembangan ide permainan "RATON" berawal dari maraknya permainan boardgame dan mulai jarangnya permainan tradisional yang dimainkan terutama permainan bentengan dan harus di lestarikan.

Beberapa dekade lalu ketika teknologi belum berkembang sepesat sekarang, anakanak menghabiskan waktu dengan bermain bersama teman-teman sebayanya. Mereka memainkan banyak permainan yang membutuhkan olah fisik seperti sepak bola, petak umpet, gobak sodor dan lain sebagainya. Dizaman sekarang, permainan tradional merupakan salah satu warisan budaya secara turun temurun (Achroni,2012).

Menurut Fealdman (2009), Permainan tradisional membutuhkan olah fisik para pemainya sehingga akan berguna untuk melatih motorik dan kognitif anak. Di era globalisasi ini anak anak sampai remaja lebih memilih untuk duduk dikamar dan bermain game digital daripada bermain dengan teman sebayanya, padahal game digital 
lebih banyak mendatangkan perilaku negatif pada anak-anak maupun remaja. Contoh perilaku negatif anak karena terlalu banyak bermain game digital adalah kecanduan dan terpengaruhnya anak pada aksi kekerasan pada game-game digital.

\section{PERANCANGAN}

1. Konsep

Terinspirasi dari permainan tradisional Bentengan yang diimprovisasi dengan mengubah skala ukuran permainan Bentengan menjadi sebuah board game. Bentengan merupakan permainan tradisional yang membutuhkan tenaga dan strategi, dimana dibutuh kerja sama kelompok untuk mengalahkan kelompok lain dengan cara menyentuh benteng lawan.

2. Dokumen Konsep

a. Deskripsi Game

- Abstraksi :

Boardgame dengan genre game edukasi dan tradisional dimana yang tercepat menyentuh benteng dia yang menang.

- Genre:

Game Edukasi

- Tema :

Tradisional

- Visual Style :

$2 D$ dan $3 D$

- Pemain :

2 Pemain

- Player Immersion :

Strategy , Memory, Luck

- Consumer Group :

12 Tahun

b. Game Technical

- Technical Form : 2D Boardgame

- View : Real Top Down

- Platform : Boardgame

- Control : Hand 
- Game Size

- Software
: $42 \times 27 \mathrm{~cm}$

: Photoshop CC 2014 dan Blender

c. Komponen game

- Package / Kotak permainan

- Kartu

- Bidak

- Poin

- Papan Permainan

- Kertas panduan bermain

3. Desain Kartu

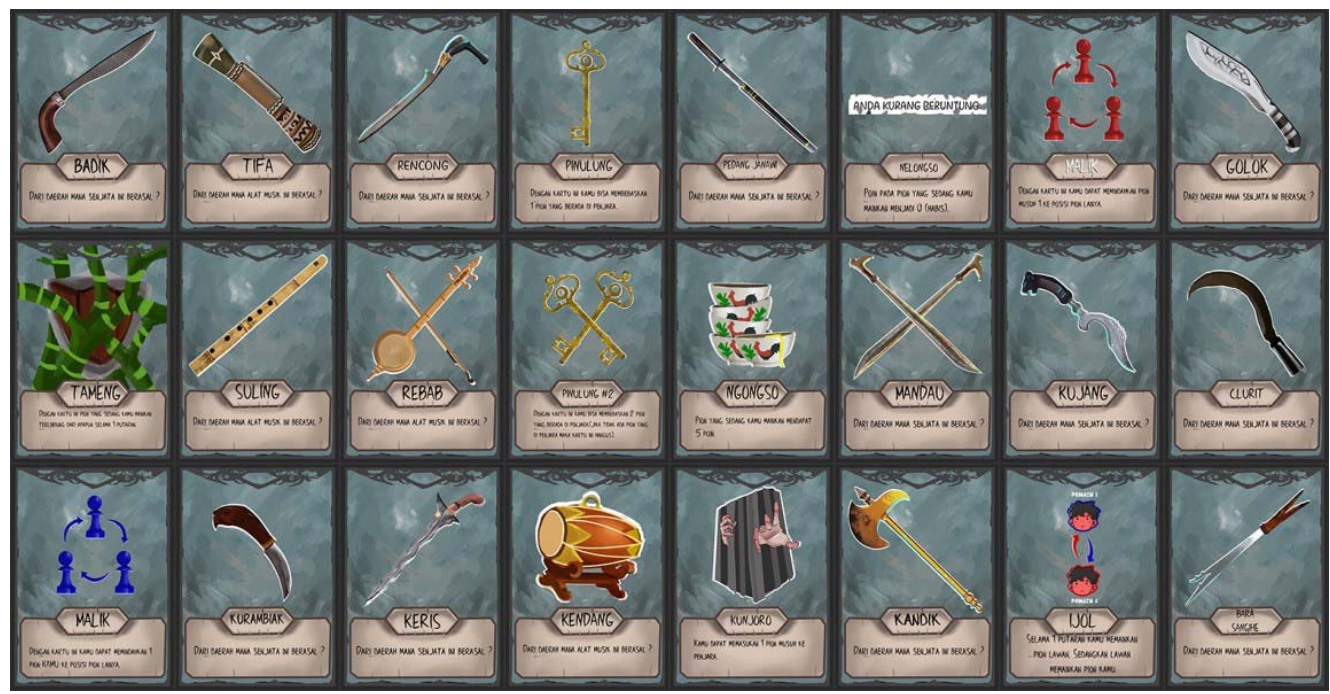

Gambar 1. Desain Seluruh Kartu 
4. Desain Backcard

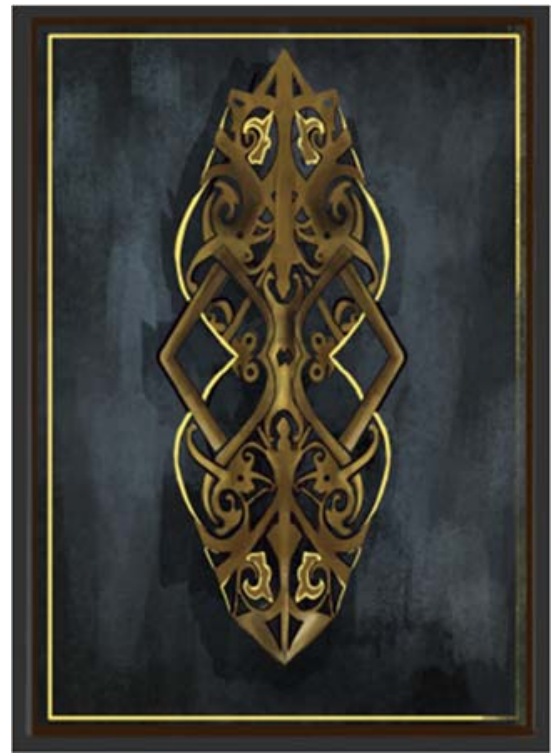

Gambar 2. Desain Backcard

5. Desain Papan Permainan

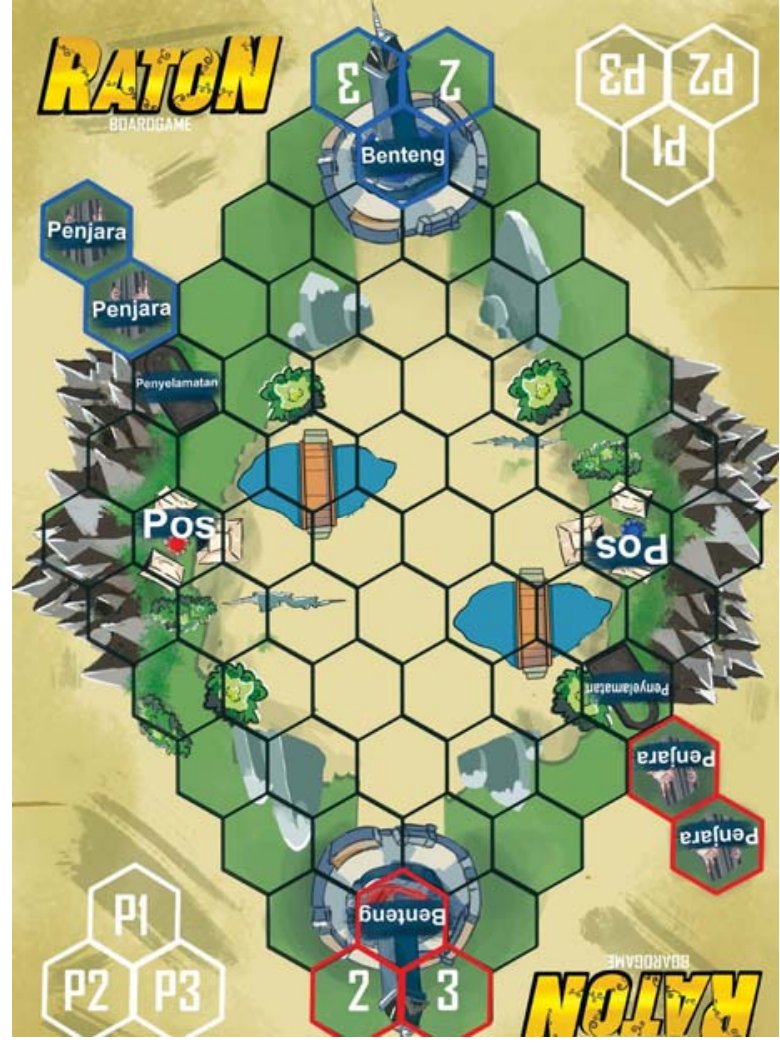

Gambar 3. Desain Papan Permainan 
6. Desain Packaging

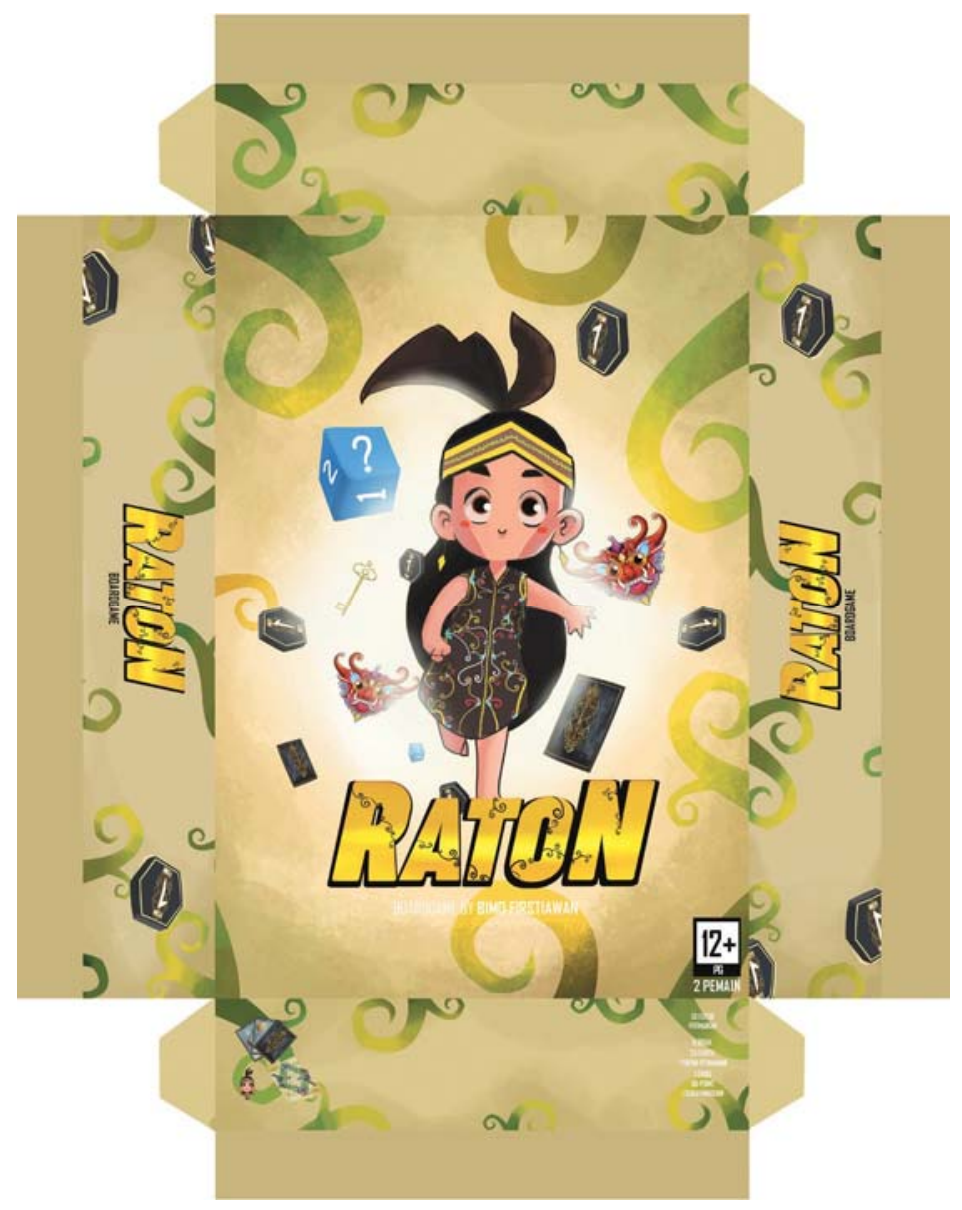

Gambar 4. Desain Packaging

\section{PERWUJUDAN}

\section{Praproduksi}

Proses praproduksi merupakan tahap awal dari proses produksi, termasuk di dalamnya menentukan konsep permainan , menata layout, dan menyusun aturan-aturan permainan gameplaynya.

a. Konsep

Konsep merupakan bentuk gambaran yang akan diproduksi. Konsep game ini pemain berlomba untuk menyentuh benteng musuh dengan cepat.

\section{b. Aturan Permainan}

Di setiap perminan maupun game terdapat cara bermain atau aturan permainan yaitu paduan dari awal permainan sampai akhir permainan yang dijelaskan 
melalui tulisan ataupun dengan gambar. "RATON" memliki aturan permainan yang terbilang rumit tapi tujuan dalam aturan permainan ini sangatlah mudah yaitu menangkap semua bidak atau pion musuh atau dengan menempati benteng musuh.

\section{c. Flowchart}

Flowchart adalah diagram bermain, yang harus ada di setiap bentuk game. Flowchart juga menentukan alur permainan yang memperjelas peraturan bermain terutama kepada produser atau supervisor. Berikut flowchart

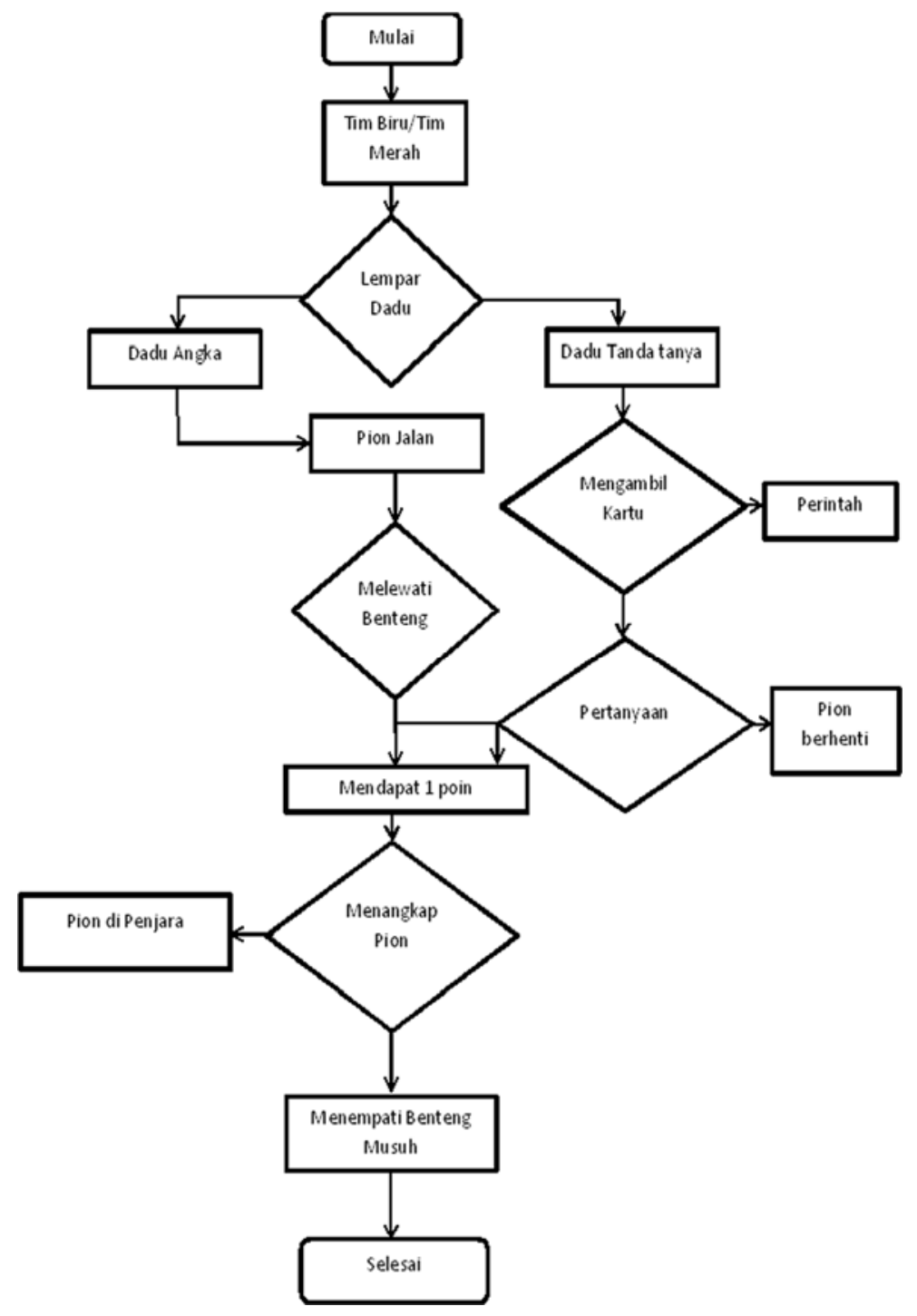

Gambar 5. Flowchart "RATON" 


\section{Produksi}

a. Desain

Dalam tahap desain, semua aset dibuat mulai dari desain pion/bidak, desain kartu, desain $3 D$ dadu, papan permainan, packaging.

b. Alpha Testing

Alpha Testing adalah tahapan dimana kita sebagai developer game mengumpulkan beberapa game tester atau orang untuk memainkan prototype game kita, tugas mereka adalah memainkan game kita dengan peraturan yang sudah kita buat. Tahap ini membantu developer game untuk mencari kelemahan dan kelebihan game secara langsung.

\section{Pascaproduksi}

a. Final Render

Final Render adalah hasil akhir semua desain yang telah dibuat dan siap dicetak dan dikemas di dalam kemasan boardgame "RATON “.

b. Packaging

Setelah semua komponen tercetak, tahap berikutnya adalah pengemasan produk. Produk dikemas serapi mungkin dan terlihat menjual baik dari segi desain ataupun tampilan kotaknya.

c. Public Testing

Merupakan uji coba permaianan untuk umum dengan upaya meperoleh respon atau masukan pada produk yang sudah jadi. Sehingga ketika pencetakan secara masal berjalan baik. Bisa juga dalam tahap ini produk dipesan atau dijual dengan cara preorder.

\section{d. Promo}

Merupakan proses mengenalkan produk ke publik melalui berbagai macam media, seperti pameran, media social, pada forum-forum boardgame dengancara membuat video promo berupa cara bermain atau preview permainanya. Promo sendiri sangat penting karena tanpa adanya promo "RATON" atau permainan lain tidak akan di kenal oleh publik. 


\section{PEMBAHASAN}

1. Elemen Formal

Penciptaan boardgame "RATON" juga memasukan beberapa unsur-unsur dari boardgame itu sendiri, di jelaskan sebagai berikut :

a. Prosedur

Game "RATON" berakhir jika salah satu pemain berhasil menyentuh benteng lawan atau menangkap seluruh bidak lawan. Setiap putaran, pemain diberi kesempatan untuk melempar dadu guna menggerakan pion sesuai hasil dadu.

b. Aturan

1) 1 pemain mendapat 3 bidak/pion yang dijalankan bergantian sesuai urutan,

2) Untuk menjalankan bidak, pemain di haruskan untuk melempar dadu.

3) Setiap bidak melewati atau meninggalkan tulisan "benteng" bidak mendapat 1 poin. Poin tersebut ditaruh ditempat yang sudah di sediakan dan sesuai dengan penomoran bidak.

4) Jika hasil dadu adalah "angka", bidak di jalankan sebanyak hasil tersebut.

5) Jika hasil dadu adalah "simbol",pemain harus mengambil kartu.

6) Terdapat 2 jenis kartu dalam 1 deck, kartu pertanyaan dan kartu perintah. Kartu pertanyaan jika dijawab dengan benar maka pemain mendapat hadiah 1 poin. Kartu perintah merupakan kartu yang memiliki fungsi yang berbeda-beda.

7) Bidak dapat menangkap bidak lawan dengan cara menjalankan bidak ke area yang ditempati bidak musuh dengan jumlah poin yang lebih sedikit atau sama banyak.

8) Bidak yang tertangkap akan diletakkan pada area "penjara", cara menyelamatkannya dengan menjalankan bidak ke area/tulisan "penyelamatan". Bidak yang telah di selamatkan akan kembali ke tempat awal permainan.

9) Permainan di anggap selesai jika bidak kamu menempati tulisan "benteng" lawan atau dengan menangkap seluruh biadak lawan.

10) "Pos" memiliki fungsi untuk mendapatkan 2 poin jika bidak melawati area tersebut. 


\section{KESIMPULAN}

1. Boardgame "RATON" merupakan pengembangan dari permainan tradisional yang bernama Bentengan;

2. Terdapat proses-proses dalam penciptaan boardgame "RATON" dari ide,konsep,layouting, membuat aturan permainan,prototype/prakarya, pembuatan aset, test play hingga packaging;

3. Boadgame "RATON" mengambil unsur-unsur kebudayaan Indonesia dari segi senjata tradisionalnya dan alat musik tradisional;

4. "RATON" merupakan permainan yang bisa dimainkan oleh banyak orang;

5. Boardgame "RATON" memiliki aturan permainan yang terbilang kompleks namun masih bisa dimengerti karena dalam pembuatan permainan masih mengambil komponen-komponen dasar dari permainan yang sudah ada.

\section{SARAN}

1. Aturan permainan sedikit kompleks untuk ukuran anak-anak.

2. Jenis-jenis kartu bisa ditambah agar lebih variatif.

3. Menambah ukuran papan permainan 


\section{DAFTAR PUSTAKA}

Achroni, Keen. 2012. Mengoptimalkan Tumbuh Kembang Anak Melalui Permainan Tradisional. Jakarta:Javalitera.

Crawford, Chris. 1984. The Art of Coputer Game Design. United States: Osborne Media.

Papalia D.E., Olds S.W, \& Feldman, R.D.2009. Human Development(Perkembangan Manusia edisi 10 buku2).(Penerj. Brian Marwensdy). Jakarta Salemba Humanika.

\section{Laman:}

Ir. Blasworo Adisuyanto Aka,MM. 2012. Olahraga Tradisional "BENTENG".

Tersedia di: http://ortrad.blogspot.com/2012/11/olahraga-tradisional- benteng.html [7 Oktober 2017]

Nelson Gustav Wisana. 2011. Manfaat Board Game di Tengah Era Digital.

Tersedia di: http://arulingame.blogspot.com/p/mengapa-board-game.html [10 Oktober 2017]

Vagansza. 2015. 51 Game Mekanik yang Kerap digunakan dalam Tablettop Game

Tersedia di: http://www.google.com/amp/boardgame.id/52-game-mekanik-yang- kerapdigunakan-dalam-tabletop-game/amp/

[20 november 2018] 